\title{
Changes in body composition in triathletes during an Ironman race
}

\section{Journal Article}

\section{Author(s):}

Müller, Sandro M.; Anliker, Elmar; Knechtle, Patrizia; Knechtle, Beat; Toigo, Marco

Publication date:

2013-09

Permanent link:

https://doi.org/10.3929/ethz-b-000071813

Rights / license:

In Copyright - Non-Commercial Use Permitted

Originally published in:

European Journal of Applied Physiology 113(9), https://doi.org/10.1007/s00421-013-2670-3 


\title{
Changes in body composition in triathletes during an Ironman race
}

\author{
Sandro Manuel Mueller • Elmar Anliker • \\ Patrizia Knechtle $\cdot$ Beat Knechtle $\cdot$ Marco Toigo
}

Received: 25 January 2013/Accepted: 29 May 2013/Published online: 9 June 2013

(C) Springer-Verlag Berlin Heidelberg 2013

\begin{abstract}
Purpose Triathletes lose body mass during an Ironman triathlon. However, the associated body composition changes remain enigmatic. Thus, the purpose of this study was to investigate Ironman-induced changes in segmental body composition, using for the first time dual-energy $\mathrm{X}$-ray absorptiometry (DXA) and peripheral quantitative computed tomography (pQCT).

Methods Before and after an Ironman triathlon, segmental body composition and lower leg tissue mass, areas and densities were assessed using DXA and pQCT, respectively, in eight non-professional male triathletes. In addition, blood and urine samples were collected for the determination of hydration status.

Results Body mass decreased by $1.9 \pm 0.8 \mathrm{~kg}$. This loss was due to $0.4 \pm 0.3$ and $1.4 \pm 0.8 \mathrm{~kg}$ decrease in fat and lean mass, respectively $(P<0.01)$. Calf muscle density was reduced by $1.93 \pm 1.04 \%(P<0.01)$. Hemoglobin, hematocrit, and plasma $\left[\mathrm{K}^{+}\right]$remained unchanged, while
\end{abstract}

Communicated by Jean-René Lacour.

S. M. Mueller · E. Anliker · M. Toigo ( $\square)$

Exercise Physiology, Institute of Human Movement Sciences,

ETH Zurich, Winterthurerstrasse 190, 8057 Zurich, Switzerland

e-mail: marco.toigo@hest.ethz.ch

P. Knechtle · B. Knechtle

Institute of General Practice and Health Services Research,

University of Zurich, Zurich, Switzerland

M. Toigo

Institute of Physiology, University of Zurich, Zurich,

Switzerland

M. Toigo

Zurich Center for Integrative Human Physiology, University

of Zurich, Zurich, Switzerland plasma $\left[\mathrm{Na}^{+}\right](P<0.05)$, urine specific gravity and plasma and urine osmolality increased $(P<0.01)$.

Conclusions The loss in lean mass was explained by a decrease in muscle density, as an indicator of glycogen loss, and increases in several indicators for dehydration. The measurement of body composition with DXA and pQCT before and after an Ironman triathlon provided exact values for the loss in fat and lean mass. Consequently, these results yielded more detailed insights into tissue catabolism during ultra-endurance exercise.

Keywords Dual-energy X-ray absorptiometry (DXA) . Peripheral quantitative computed tomography (pQCT) . Glycogen · Dehydration

$\begin{array}{ll}\text { Abbreviations } \\ \text { Ar.muscle } & \text { Total muscle cross-sectional area } \\ \text { Ar.fat } & \text { Total fat cross-sectional area } \\ \text { BIA } & \text { Bioelectrical impedance analysis } \\ \text { DXA } & \text { Dual-energy X-ray absorptiometry } \\ \text { MPB } & \text { Muscle protein breakdown } \\ \text { MPS } & \text { Muscle protein synthesis } \\ \text { pQCT } & \text { Peripheral quantitative computed tomography } \\ \text { ROI } & \text { Region of interest } \\ \text { SD } & \text { Standard deviation } \\ \text { vBMC } & \text { Volumetric bone mineral content }\end{array}$

Introduction

A triathlon is an event that is composed of the continuous and sequential completion of three different endurance disciplines. The most popular and widely recognized triathlon combines swimming, cycling, and running, and is performed over either a short or long distance. The short-course 
triathlon, which is included in the Olympic Games, is comprised of $1.5 \mathrm{~km}$ swimming, $40 \mathrm{~km}$ cycling and $10 \mathrm{~km}$ running. The long-course triathlon, i.e., the so-called Ironman triathlon, involves $3.8 \mathrm{~km}$ swimming, $180 \mathrm{~km}$ cycling and $42.2 \mathrm{~km}$ running (Lepers 2008). For the Ironman triathlon, a World Cup series is available for competitors who aim at qualifying for the World Championship race in Hawaii.

Although participants in Ironman events are subjected to severe stress and strain, popularity and status of Ironman triathlon are growing (Lepers 2008). Despite the popularity of these events, there has been little field research to measure the changes in body composition and fluid balance of triathletes during these events. It has been shown that male Ironman finishers lose $2.3 \%$ body mass (Rogers et al. 1997). An even higher average loss of body mass (-4.6\%) has been reported for male triathletes competing in the South African Ironman (Speedy et al. 2001). Rogers et al. (1997) postulated that $\sim 60 \%$ of the loss in body mass during a long-distance triathlon is due to factors other than pure fluid loss. The presumed mass loss includes loss of fat and glycogen, and the metabolic water stored within glycogen (Knechtle et al. 2010).

Knechtle et al. (2010) recently lent further credence to the notion that mass loss during an Ironman triathlon originates from sources other than fluid by calculating from skin-fold thicknesses that 55.6 and $27.9 \%$ of lost body mass can be accounted for by the loss in skeletal muscle mass and fat mass, respectively. These authors also speculated that the loss of skeletal muscle mass was due to a depletion of intramyocellular lipid and/or glycogen, but not muscle protein. As suggested by Knechtle et al. (2010), the putative loss of endogenous energy stores could partly be caused by the substantial energy deficit attained during an Ironman triathlon. In fact, Kimber et al. (2002) calculated that male Ironman triathletes expend about 41.9 MJ per Ironman race, while ingesting about $16.7 \mathrm{MJ}$, resulting in an energy deficit of about 25.2 MJ.

Up to date, body composition changes in response to an Ironman triathlon were solely estimated from skin-fold thickness measurements and bioelectrical impedance analysis (BIA). However, the skin-fold thickness approach is unsuitable for longitudinal comparisons because (1) the skin-fold equations to predict body fat may not be valid in populations other than those from which they were derived, (2) the accuracy in individuals is invariably poor and also varies in relation to body fatness and-in the special case of long-distance endurance events-the development of edema (Knechtle et al. 2009), and (3) for the assessment of skeletal muscle mass this approach is particularly inappropriate since no index of this body mass component is measured (Wells and Fewtrell 2006). Similarly, BIA equations are populations specific and perform poorly in healthy individuals. In the case of Ironman triathletes, BIA accuracy in individuals may be confounded by the presence of edema, changes in hydration status and/or skin temperature, and hyperthermia.

A further factor limiting insights into the fat and muscle remodeling during an Ironman triathlon is the inability of both the skin-fold thickness approach, and hand-foot or foot-foot BIA to provide information about the segmental (i.e., arms, legs, trunk, and gluteofemoral and abdominal regions) changes in body composition. In this study, we aimed at quantifying the change in segmental body composition in male triathletes participating in an Ironman event, using dual-energy X-ray absorptiometry (DXA) and peripheral quantitative computed tomography (pQCT). DXA provides estimates of fat, lean and bone mass for several body segments, i.e. arms, trunk, abdominal ('android') and gluteofemoral ('gynoid') regions, and legs. pQCT further offers insights into potential changes (prevs. post-race) in muscle density, muscle and fat area, bone variables. Although DXA and pQCT measurements are generally reliable, precise and practical, physical activity and nutrition might influence test-retest reliability (Nana et al. 2012a). Therefore, we applied a tight standardization with respect to positioning and measurements point in time to limit a possible increase in the typical error of measurement (Nana et al. 2012b).

Since ultra-endurance exercise might alter whole-body water content, and, as a consequence whole-body lean mass, blood and urine samples were collected for the determination of hydration status. We hypothesized that an Ironman triathlon is associated with a net energy deficit, leading to a loss of total body mass, fat mass, lean mass, and muscle density. However, based on the relatively slow bone remodeling rate and the expected low calcium loss through sweating, we assumed that whole-body bone mass and cortical and trabecular densities of tibial bone would remain unaltered during this half-day competition. We further assumed that triathletes lose whole-body water during the event, and that the loss of whole-body water is associated with changes in lean mass.

\section{Methods}

\section{Participants}

Eight male non-professional Ironman triathletes participating in the 2010 'Ironman Switzerland' held in Zurich were recruited for this study. Participants were (mean \pm SD) $43.8 \pm 5.5$ years old, weighed $73.5 \pm 9.9 \mathrm{~kg}$, and had a body mass index of $22.8 \pm 2.6 \mathrm{~kg} \mathrm{~m}^{-2}$. After completing a routine health questionnaire, the participants were informed about the applied procedures and about the associated risks. 
The participants then signed an informed consent. All experiments were approved by the ethics committee of the canton of Zurich, and the study was performed in accordance with the ethical standards laid down in the Declaration of Helsinki for human experimentation.

\section{Study design and race}

Before and after the 'Ironman Switzerland', we performed measurements to assess body composition. To this end, participants reported to the laboratory twice. During the first visit, which took place 2-3 days before the race, DXA and pQCT were performed in sequential order. Participants reported to the laboratory at 08:00 am after an overnight fast and without prior exercise. Contrary to body composition, blood and urine samples were obtained on-site (at the finish line) before and after the race. After the race, participants were not allowed to consume food or fluids until the DXA and pQCT were completed. These measurements were performed $3 \mathrm{~h}$ after arrival at the finish line. We chose a $3 \mathrm{~h}$ delay to ensure a re-equilibration with respect to fluid distribution and thus allow a comparison to the resting condition while maintaining stable plasma osmolality.

The Ironman started at 07:00 a.m. At that time air and water temperature was 14 and $20^{\circ} \mathrm{C}$, respectively. Wetsuits were allowed due to the low water temperature. At the start, the sky was clear and became cloudy slowly during the afternoon and evening. The highest temperature, $23.2{ }^{\circ} \mathrm{C}$, was reached in the afternoon. Humidity was at $69 \%$ in the morning and dropped to $37 \%$ in the afternoon. Barometric pressure was at $1,021.5 \mathrm{hPa}$ at the start and rose to $1,014.9 \mathrm{hPa}$ in the afternoon. The athletes had to swim two laps in the Lake of Zurich to cover the $3.8 \mathrm{~km}$ distance, and then had to cycle two laps of $90 \mathrm{~km}$ each, followed by running four laps of $10.5 \mathrm{~km}$ each. In the cycling part, the highest point to climb from Zurich (400 m above sea level) was the 'Forch' (700 m above sea level), while the running course was flat in the City of Zurich. Nutrition was provided for the cycling and running courses by the organizers. They offered bananas, energy bars, energy gels and carbohydrate drinks as well as caffeinated drinks and water on the cycling course. On the running course, in addition to the aforementioned nutrition, various fresh and dried fruits, nuts, chips, salt bars and soup were provided.

\section{Experimental procedures}

\section{Dual-energy X-ray absorptiometry (DXA)}

Before the DXA measurements, we assessed body mass with a SECA (model 761) weighing scale (Polymed, Glattbrugg, Switzerland) and body height with a SECA (model 206) wall tape (Polymed, Glattbrugg, Switzerland). Total body DXA measurements were performed with a Lunar iDXA ${ }^{\mathrm{TM}}$ absorptiometer (GE Healthcare, Madison, WI, USA) according to the manufacturer's specifications. The appropriate scan mode was chosen to adjust the X-ray attenuation for the thickness of each participant. For our experiments, all scans were conducted in the standard $(0.13-0.25 \mathrm{~m})$ mode, which requires $\sim 6$ min of scan time with an effective radiation dose of $4.7 \mu \mathrm{Sv}$ (manufacturer's technical data). Scan analysis was performed using GE encore software version 11.40.004. Total body fat and lean mass, percentage fat from tissue, as well as segmental (abdominal and gluteofemoral regions) fat and lean mass were used for subsequent analyses. The abdominal ('android') region of interest (ROI) was defined by the manufacturer's software as follows: lower boundary at the pelvis cut and upper boundary above the pelvis cut by $20 \%$ of the distance between the pelvis and neck cuts; lateral boundaries are the arm cuts. The gluteofemoral ('gynoid') ROI was defined by the manufacturer's software as follows: upper boundary below the pelvis cut line by 1.5 times the height of the android ROI and gynoid ROI height equal to two times the height of the android ROI, lateral boundaries are the outer leg cuts. The right lower leg ROI was defined as follows: ROI upper boundary $=$ horizontal line between femur and tibia; lower boundary $=$ horizontal line through the tibio-talar joint; lateral boundaries $=$ outer lower leg cuts. In our laboratory, the typical errors expressed as coefficients of variation for DXA total fat mass, total lean mass, and total bone mineral content are 1.6, 0.9 and $0.4 \%$, respectively. These values correspond to the recently published results of $1.3,1.0$, and $1.1 \%$ for total fat mass, total lean mass and total bone mineral content, respectively (Nana et al. 2012a).

\section{Peripheral quantitative computed tomography ( $p Q C T$ )}

An XCT 3000 Scanner (Stratec, Pforzheim, Germany) was used for pQCT. This apparatus measures attenuation of $\mathrm{X}$-rays, which are linearly transformed into hydroxyapatite (HA) densities. HA density measurements were calibrated with respect to water, which was set to $60 \mathrm{mg} \mathrm{HA} \mathrm{cm}^{-3}$. Fat resulted in a HA equivalent density of about $0 \mathrm{mg}$ $\mathrm{HA} \mathrm{cm}^{-3}$ (Augat et al. 1998). HA equivalent densities were automatically calculated from the attenuation coefficients by employing the manufacturer's phantom, which itself was calibrated with respect to the European Forearm Phantom (EFP; QRM, Erlangen, Germany). The apparatus was calibrated once every five measurements (for single slice-standard phantom) and before the pre and post test sessions (for multiple slice-cone phantom). Section images were obtained from the calf scout view of the right tibio-talar joint. Scans were obtained at 4 (epiphysis), 14, and $66 \%$ (diaphysis) of the tibia length. We measured the 
length of the tibia based on anatomical landmarks (from knee joint line to medial malleolus) using a ruler. For all measurements, the angle between the foot and tibia was adjusted to $120^{\circ}$.

According to the manufacturer, the radiation dose is $0.9 \mu \mathrm{Sv}$ per single pQCT scan (whole body effective dose). Hence, the estimated total radiation dose for three images was $2.7 \mu \mathrm{Sv}$. Images were analyzed with the integrated XCT software in its version 6.00. Volumetric bone mineral content (vBMC) was assessed with the detection threshold set to 180 and $710 \mathrm{mg} \mathrm{cm}^{-3}$ for epiphyseal and diaphyseal scans, respectively. Total muscle and fat cross-sectional areas (Ar.muscle and Ar.fat, respectively) were assessed by defining ROIs based on a density threshold of $35 \mathrm{mg} \mathrm{cm}^{-3}$. The typical error of the measurement expressed as a coefficient of variation corresponds to $0.5 \%$ for vBMC at the $14 \%$-site (Anliker et al. 2012), while the test-retest coefficient of variation for muscle density is $0.85 \%$ (Goodpaster et al. 2000).

\section{Blood and urine analyses}

Venous blood samples were drawn and urine samples were collected. Two Sarstedt S-Monovettes (plasma gel, $7.5 \mathrm{ml}$ ) for chemical and 1 Sarstedt S-Monovette (EDTA, $2.7 \mathrm{ml}$ ) (Sarstedt, Nümbrecht, Germany) for hematological analysis were drawn. Monovettes for plasma were centrifuged at 3,000 g for $10 \mathrm{~min}$ at $4{ }^{\circ} \mathrm{C}$. Plasma was collected and stored on ice. Urine was collected in Sarstedt monovettes for urine $(10 \mathrm{ml})$. Blood and urine samples were transported immediately after collection to the laboratory and were analyzed within $6 \mathrm{~h}$. Immediately after arrival at the finish line, identical measurements were applied. In the venous blood samples, hemoglobin, hematocrit, osmolality, plasma $\left[\mathrm{Na}^{+}\right]$and plasma $\left[\mathrm{K}^{+}\right]$were determined. Hematologic parameters were determined using ADVIA ${ }^{\circledR} 120$ (Siemens Healthcare Diagnostics, Deerfield, IL, USA). Plasma parameters were measured using COBAS INTEGRA ${ }^{\circledR} 800$ (Roche, Mannheim, Germany). Osmolality in plasma was determined using Fiske ${ }^{\circledR}$ Modell 210 Mikro-Osmometer (IG Instrumenten-Gesellschaft AG, Zurich, Switzerland). In the urine samples, specific gravity was analyzed by using Clinitek Atlas ${ }^{\circledR}$ Automated Urine Chemistry Analyzer (Siemens Healthcare Diagnostics, Deerfield, IL, USA). Osmolality in urine samples was determined using Fiske ${ }^{\circledR}$ Modell 210 Mikro-Osmometer (IG Instrumenten-Gesellschaft AG, Zurich, Switzerland). The accuracy of the osmometer is \pm 2 mosm $\mathrm{kg} \mathrm{H}_{2} \mathrm{O}^{-1}$ between 0 and 400 mosm $\mathrm{kg} \mathrm{H}_{2} \mathrm{O}^{-1}$. For the measurement of urine specific gravity, the Clinitek Atlas ${ }^{\circledR}$ device agrees within \pm 0.002 SG units in $95 \%$ of the samples with a total solids meter (Lott et al. 1995). Percentage change in plasma volume was determined according to Strauss et al. (1951).

\section{Energy intake}

Immediately after arrival at the finish line, the athletes completed a questionnaire about their intake of solid food and fluids. The investigator prepared a paper where each aid station with the offered food and fluids was indicated. The athletes marked the kind as well as the amount of food and fluid consumed at each aid station. They also recorded additional food and fluid intake provided by the support crew as well as the intake of salt tablets and other supplements. The composition of fluids and solid food were determined according to the reports of the athletes using a food table (Kirchhoff 2002). Intake of energy, fluid volume, sodium and potassium was calculated accordingly.

\section{Statistics}

Data are presented as mean values \pm standard deviations (SD). Normality of data and homogeneity of variance were visually ascertained by Q-Q-plots and Levene's Test for equality of variances, respectively. To assess differences in body composition, blood and urine values, tissue areas and densities, a two-way repeated-measures ANOVA having one level of condition and two levels of time (pre and post) was used. The assumption of sphericity was tested using Mauchly's test. In the case of violation of the assumption of sphericity, degrees of freedom were corrected using Greenhouse-Geisser corrected estimates of sphericity. Pearson correlations were performed to assess the relationships between variables, and one-way ANOVA was performed to analyze the relative fat loss between different body segments. We used SPSS 20.0 statistical software (SPSS, Chicago, USA) for all statistical analyses. Statistical significance was set at $P<0.05$. Due to the low number of participants, a post-hoc power analysis was performed for the most important results [G*Power 3.1.7 (Faul et al. 2007)]. This analysis was based on the statistical significance, the effect size and the sample size.

\section{Results}

Race performance, energy intake, and body fluids

Participants finished the race within 11:27 \pm 1:24 h. Energy intake during the race was $913 \pm 238 \mathrm{~kJ} \mathrm{~h}^{-1}$ or $145 \pm 42 \mathrm{~kJ} \mathrm{~kg}^{-1} \mathrm{~h}^{-1}$. Carbohydrate, protein, and fat intake were $0.71 \pm 0.12,0.021 \pm 0.010$, and $0.006 \pm$ $0.003 \mathrm{~g} \mathrm{~kg}^{-1} \mathrm{~h}^{-1}$, respectively. During the race, participants consumed $0.71 \pm 0.37 \mathrm{dm}^{3} \mathrm{~h}^{-1}$ of fluids, which corresponded to a fluid intake of $0.10 \pm 0.04 \mathrm{dm}^{3} \mathrm{~kg}^{-1}$ body mass. Estimated sodium intake was $379 \pm 190 \mathrm{mg} \mathrm{h}^{-1}$, corresponding to $59.6 \pm 28.2 \mathrm{mg} \mathrm{kg}^{-1}$ body mass sodium 
intake. For potassium, the athletes ingested $197 \pm$ $93 \mathrm{mg} \mathrm{h}^{-1}$, i.e., $30.9 \pm 13.5 \mathrm{mg} \mathrm{kg}^{-1}$ body mass.

Body mass and composition, and blood variables

Participants lost $2.4 \pm 1.1 \%$ body mass, which in absolute terms corresponded to a decrease of $1.9 \pm 0.8 \mathrm{~kg}$ body mass $(1-\beta=0.999)$. This decrease was due to the decrease in whole-body fat and lean mass $[-0.4 \pm 0.3$ $(1-\beta=0.932)$ and $-1.4 \pm 0.8 \mathrm{~kg} \quad(1-\beta=0.985)$, respectively] (Table 1). Significant $(P<0.05)$ mass loss occurred in all DXA body segments except for the arms, while fat mass significantly decreased in the legs, trunk, and android region. There was no difference in the relative decrease in total, lean and fat mass between these body segments, although the relative fat loss in the android region tended to be highest (Fig. 1). Lean mass decreased significantly only in the legs (Table 1). However, wholebody and segmental fat percentages and bone masses remained unaffected by the race (Table 1).

Hemoglobin, hematocrit, and plasma $\left[\mathrm{K}^{+}\right]$remained unchanged, and plasma $\left[\mathrm{Na}^{+}\right](1-\beta=0.731)$, urine specific gravity $(1-\beta=0.994)$ and osmolality in both plasma $(1-\beta=0.945)$ and urine $(1-\beta=0.957)$ increased (Table 2). The change in plasma $\left[\mathrm{Na}^{+}\right]$correlated with the change in plasma osmolality $(r=0.74$, $P=0.038$ ). The percentage change in body mass showed no correlation with either post-race plasma osmolality $(r=-0.61, P>0.05)$ or post-race plasma sodium $(r=$ $-0.36, P>0.05)$. However, the percentage change in body mass was significantly and negatively correlated to the percentage change in plasma osmolality (Fig. 2).

Lower leg tissue areas and densities

Right tibial bone area, fat area, muscle area and thus total area did not change at the three assessed sites (i.e. 4, 14, and $66 \%$ tibia length) during the Ironman triathlon (Table 3 ). In addition, volumetric bone mineral content (4, $14,66 \%)$ and trabecular $(4 \%)$ as well as cortical (14, $66 \%$ ) bone mineral density remained unaltered. On the contrary, muscle density at the $66 \%$-site decreased by $1.93 \pm 1.04 \%(1-\beta=0.993$; Table 3$)$.

\section{Discussion}

Several new findings could be gained through this study, in which, for the first time, DXA and pQCT were used to determine body composition changes after an Ironman triathlon. First, the $2.4 \%$ decrease in total body mass could be attributed to a 28 and $72 \%$ loss in fat and lean

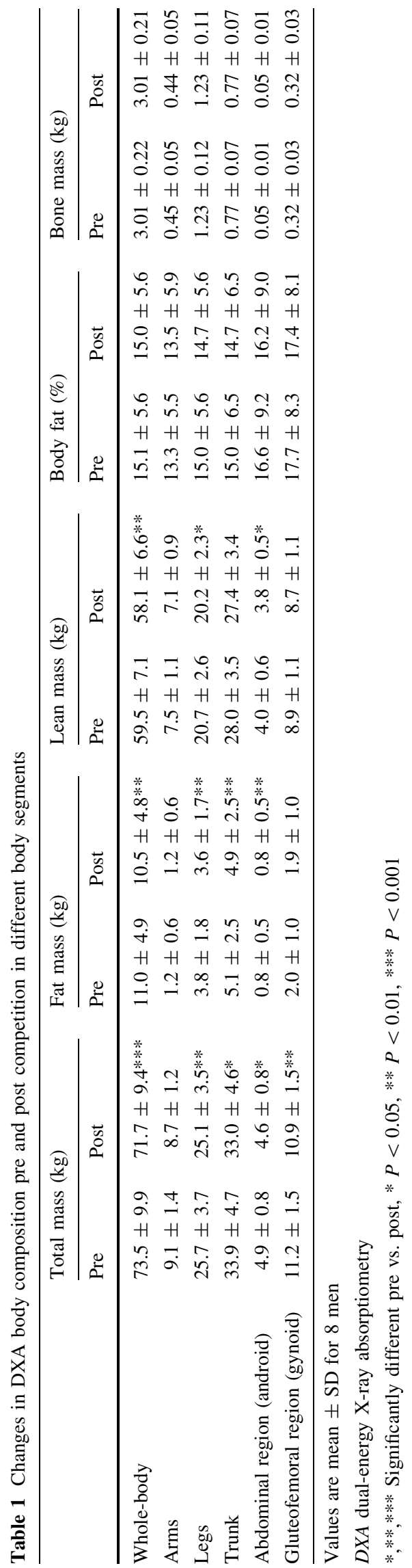




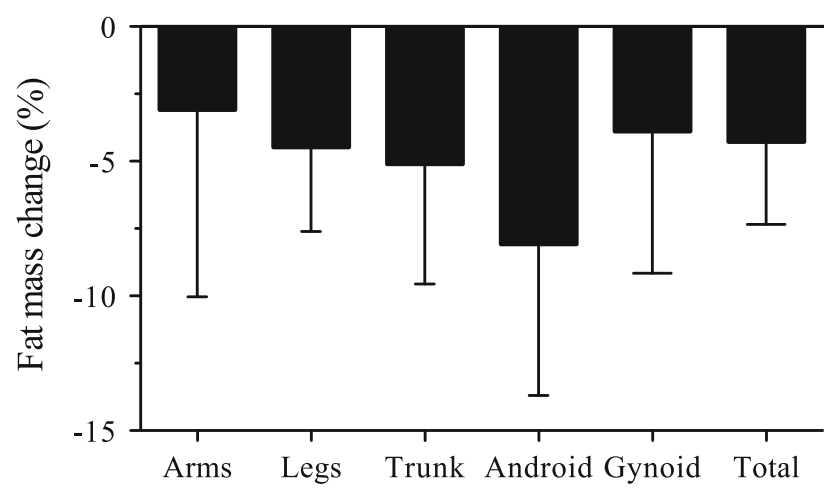

Fig. 1 Relative change in segmental fat mass during the Ironman triathlon for eight male triathletes

mass, respectively. Second, both leg lean mass and lower leg muscle density decreased during the triathlon.

We found that during an Ironman race, the decrease in fat mass occurred mainly in the legs and the body core, which reflects the fact that most of the work during the triathlon is performed with these body parts. In the legs, the fat loss could in principle be explained by a reduction in extra- and/or intramuscular fat. Moreover, it might preferentially occur either in the thighs or the lower legs. Our pQCT results clearly show that in the lower leg, there was neither a reduction in extramuscular fat area nor an increase in muscle density. Notably, the latter would have been expected in the case of a sole reduction in intramuscular lipid content (Goodpaster et al. 2000). Our DXA results thus indicated that the male triathletes lost lipids in their thighs, while the pQCT measurement showed that fat area and mass in the lower legs most likely remained unchanged. Consequently, we deduce that the lost fat mass in the legs originated from the thighs and therein, mainly form intramuscular triglyceride stores. In fact, it was previously shown that prolonged exercise decreases muscle triglyceride stores (Essen 1977; Romijn et al. 1993). Surprisingly, we found that the relative fat loss in the android region was the highest. The reason for this probably was that the fat percentage in this segment also was high before the race. The condition of a high android fat percentage is typical for men, since they tend to store fat predominantly in this body segment. Fat mobilization from the android region may thus have played a major role in covering part of the substantial energy expenditure associated with the present Ironman contest.

The further loss of body mass can be attributed to a loss in lean mass. In the DXA two-component soft tissue model, lean mass comprises water, proteins, glycogen and non-bone minerals (Pietrobelli et al. 1996). Thus, the decrease in lean mass was due to a decrease in one or several of its constituents. Furthermore, pQCT muscle density of the calf muscle was reduced after the competition. The reduction in muscle density can theoretically (Bushberg et al. 2002) be attributed to three reasons: (1) glycogen loss, (2) protein breakdown, and (3) increase in intramyocellular lipids. Importantly, changes in intramuscular water content do not influence muscle density (Ward and Lieber 2005). An increase in intramyocellular lipids is unlikely to have occurred in our study, because the participants showed a decrease in fat mass in the legs. Conversely, both a reduction in muscle protein and glycogen content might provide valid explanations for the reduction in muscle density, irrespective of possible changes in water content.

In mechanistic terms, any reduction in muscle protein content is the result of a negative net protein balance. A negative net protein balance ensues whenever muscle protein breakdown (MPB) rates exceed muscle protein synthesis (MPS) rates. Consequently, during ultra-endurance type exercise a loss of muscle protein could in principle occur if MPS was reduced and/or MPB increased. While it has been shown in rodents that exercise/muscle contractions can suppress MPS (Bylund-Fellenius et al. 1984), the few studies examining the impact of endurance exercise on whole body and/or MPS rates in humans have yielded equivocal results. Although some studies reported decreases (Wolfe et al. 1982) of exercise on MPS, others showed no effect (Carraro et al. 1990) or increases (Beelen et al. 2011; Koopman et al. 2004). The different exercise intensities used in these studies might account for the
Table 2 Results of the hematological and urinary parameters before and after the race

\footnotetext{
Values are mean \pm SD for 8 men

*, ** Significantly different pre

vs. post, $* P<0.05$,

** $P<0.01$
}

\begin{tabular}{lccr}
\hline & \multicolumn{1}{c}{ Pre } & Post & Change (\%) \\
\hline Hemoglobin $\left(\mathrm{g} \mathrm{dl}^{-1}\right)$ & $15.1 \pm 0.4$ & $15.3 \pm 0.5$ & $1.6 \pm 4.5$ \\
Hematocrit $(\%)$ & $44.8 \pm 1.9$ & $44.7 \pm 2.2$ & $-1.0 \pm 6.4$ \\
Blood plasma & & & \\
{$\left[\mathrm{Na}^{+}\right]\left(\mathrm{mmol} \mathrm{l}^{-1}\right)$} & $139.2 \pm 1.7$ & $140.8 \pm 2.3^{*}$ & $1.1 \pm 1.0^{*}$ \\
{$\left[\mathrm{~K}^{+}\right]\left(\mathrm{mmol} \mathrm{l}^{-1}\right)$} & $4.5 \pm 0.3$ & $4.6 \pm 0.5$ & $2.1 \pm 12.9$ \\
Osmolality $\left(\mathrm{mosmol} \mathrm{kg} \mathrm{H} \mathrm{O}^{-1}\right)$ & $297.0 \pm 2.9$ & $306.6 \pm 6.7^{* *}$ & $3.2 \pm 2.2^{* *}$ \\
Urine & & & \\
Specific gravity $\left(\mathrm{g} \mathrm{ml}^{-1}\right)$ & $1.0120 \pm 0.0050$ & $1.0270 \pm 0.0040^{* *}$ & $1.5 \pm 0.8^{* *}$ \\
Osmolality $\left(\mathrm{mosmol} \mathrm{kg} \mathrm{H} \mathrm{O}^{-1}\right)$ & $520 \pm 240$ & $875 \pm 64^{* *}$ & $105 \pm 94^{* *}$ \\
\hline
\end{tabular}


apparent discrepancy, although differences in the fed/fasted state of the study participants are probably more important. In fact, all studies showing decreases or no effect were performed in the fasted state while those showing increases were performed in the fed state [i.e., 0.7-1.0 g carbohydrate $\mathrm{kg}^{-1} \mathrm{~h}^{-1}$ or $0.7-0.8 \mathrm{~g}$ carbohydrate plus $0.2-0.25 \mathrm{~g}$ protein $\mathrm{kg}^{-1} \mathrm{~h}^{-1}$ (Beelen et al. 2011; Koopman et al. 2004)]. The Ironman athletes participating in the present study consumed 0.7 and $0.01 \mathrm{~g} \mathrm{~kg}^{-1} \mathrm{~h}^{-1}$ of carbohydrate and protein, respectively, which corresponds to 70-100\% of the carbohydrate and $\sim 5 \%$ of the protein amount used in the studies by Beelen et al. (2011) and Koopman et al. (2004), in which an increase in MPS was detected. At present, the dose-response relationship for the increase in MPS with carbohydrate feeding during long-term continuous endurance exercise is unknown. However, it is reasonable to assume that the amount of carbohydrate supplied during the herein reported Ironman race was

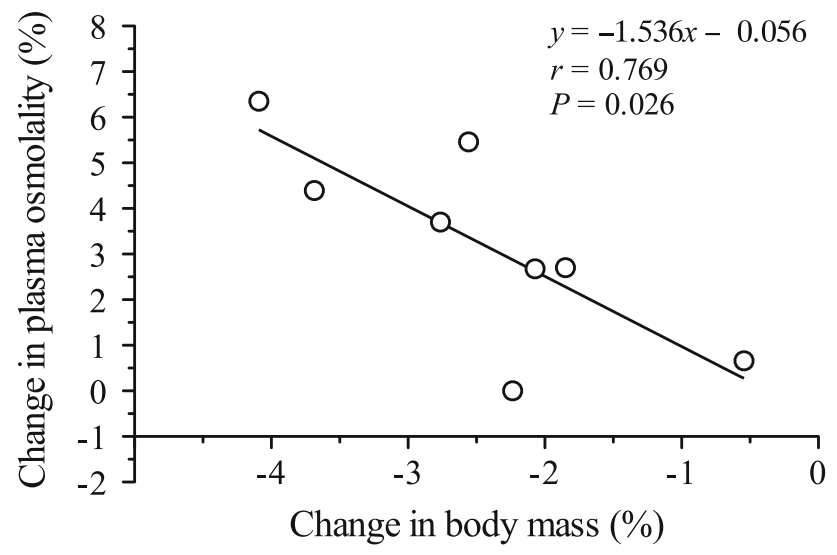

Fig. 2 Relationship between the percent changes in plasma osmolality and body mass for eight male triathletes participating in an Ironman event sufficiently high, at least to prevent the decrease in MPS otherwise observed with exercise in the fasted state (Wolfe et al. 1982). Furthermore, co-ingestion of carbohydrate and protein during prolonged exhaustive moderate-intensity exercise in endurance-trained athletes not only increases MPS but also decreases MBP, resulting in a positive net protein balance (Koopman et al. 2004). Although skeletal muscle is capable of oxidizing selected amino acids during certain exercise conditions, endurance exercise in the fed state does not appear to result in significant increases in amino acid utilization (Hargreaves and Snow 2001). It can be deduced from these data that the contribution of amino acid oxidation to total energy expenditure during this Ironman race in the fed state might be negligible, and, consequently, that the observed decrease in leg lean mass $(-0.5 \mathrm{~kg})$ has resulted from a decrease in muscle glycogen.

We showed that pQCT calf muscle density decreased by $1.93 \%$. Assuming a true muscle density of about $1.0835 \mathrm{~g} \mathrm{~cm}^{-3}$ [average of 1.1120 and $1.0550 \mathrm{~g} \mathrm{~cm}^{-3}$ from 4 and $37 \%$ formaldehyde-fixed muscle tissue (Ward and Lieber 2005)] and a lower leg muscle volume of $1,170.9 \mathrm{~cm}^{3}$ [soleus $497.8 \mathrm{~cm}^{3}$ plus tibialis anterior $152.7 \mathrm{~cm}^{3}$ (Maganaris et al. 2001); plus gastrocnemius medialis $298.4 \mathrm{~cm}^{3}$ and lateralis $222.0 \mathrm{~cm}^{3}$ (Jeng et al. 2012)], total glycogen mass loss in the lower legs amounted to $0.048 \mathrm{~kg}(2 \times 0.024 \mathrm{~kg})$. Assuming a similar decrease in muscle density in the thigh muscles, and a quadriceps and knee flexor muscle volume of 2,053.0 and $800 \mathrm{~cm}^{3}$, respectively, another $0.120 \mathrm{~kg}$ of glycogen mass $(2 \times 0.060 \mathrm{~kg})$ were lost in the thighs. Altogether, we calculated that glycogen mass in the legs decreased by $0.168 \mathrm{~kg}(2 \times 0.084 \mathrm{~kg})$. As each gram of stored glycogen binds 3-4 g of water (Olsson and Saltin 1970), the decrease in DXA lean mass for both legs should amount to $0.504-0.672 \mathrm{~kg}$. This calculated value corresponds well to

Table 3 Values of the peripheral quantitative computed tomography pre and post competition on 3-sites of tibia length

\begin{tabular}{|c|c|c|c|c|c|c|}
\hline & \multicolumn{2}{|c|}{ Right tibia (4\%) } & \multicolumn{2}{|c|}{ Right tibia (14\%) } & \multicolumn{2}{|c|}{ Right tibia (66\%) } \\
\hline & Pre & Post & Pre & Post & Pre & Post \\
\hline $\operatorname{vBMC}\left(\mathrm{g} \mathrm{cm}^{-1}\right)$ & $4.05 \pm 0.39$ & $4.02 \pm 0.40$ & $3.11 \pm 0.31$ & $3.10 \pm 0.32$ & $4.88 \pm 0.44$ & $4.88 \pm 0.47$ \\
\hline vBMD.tb $\left(\mathrm{mg} \mathrm{cm}^{-3}\right)$ & $242 \pm 32$ & $242 \pm 33$ & - & & - & \\
\hline vBMD.ct $\left(\mathrm{mg} \mathrm{cm}^{-3}\right)$ & - & & $1121 \pm 24$ & $1122 \pm 24$ & $1101 \pm 29$ & $1100 \pm 27$ \\
\hline Muscle density $\left(\mathrm{mg} \mathrm{cm}^{-3}\right)$ & - & & - & & $77.9 \pm 1.0$ & $76.4 \pm 1.3^{* *}$ \\
\hline Ar.bone $\left(\mathrm{cm}^{2}\right)$ & $13.0 \pm 1.7$ & $13.0 \pm 1.7$ & $5.2 \pm 0.5$ & $5.2 \pm 0.6$ & $7.1 \pm 0.8$ & $7.2 \pm 0.9$ \\
\hline Ar.muscle $\left(\mathrm{cm}^{2}\right)$ & $19.0 \pm 1.8$ & $19.4 \pm 1.5$ & $25.7 \pm 2.8$ & $24.9 \pm 2.4$ & $88.0 \pm 11.0$ & $86.0 \pm 10.0$ \\
\hline Ar.fat $\left(\mathrm{cm}^{2}\right)$ & $4.2 \pm 1.9$ & $3.9 \pm 1.7$ & $4.8 \pm 2.8$ & $5.0 \pm 3.1$ & $13.3 \pm 7.7$ & $13.3 \pm 7.0$ \\
\hline Ar.tot $\left(\mathrm{cm}^{2}\right)$ & $38.4 \pm 3.1$ & $38.4 \pm 2.8$ & $37.1 \pm 4.2$ & $36.6 \pm 3.8$ & $110.0 \pm 15.0$ & $107.0 \pm 13.0$ \\
\hline
\end{tabular}

Values are mean $\pm \mathrm{SD}$ for 8 men

$v B M C$ volumetric bone mineral content, $v B M D . t b$ trabecular volumetric bone mineral density, $v B M D . c t$ cortical volumetric bone mineral density, Ar.bone bone area, Ar.muscle muscle area, Ar.fat fat area, Ar.tot total cross-sectional area

** Significantly different pre vs. post at $P<0.01$ 
the measured decrease in DXA leg lean mass of $0.500 \mathrm{~kg}$, demonstrating that our data obtained from DXA and pQCT are internally consistent. The $0.168 \mathrm{~kg}$ of lost glycogen corresponds to a loss of glycogen of $32.5 \mathrm{~g} \mathrm{~kg}^{-1}$ dry muscle [wet:dry mass $=4: 1$ (Mougios 2006)], which in turn equals a loss in muscle glycogen concentration of $\sim 200 \mathrm{mmol} \mathrm{kg}^{-1}$ dry mass [molecular mass of glycogen: $162 \mathrm{~g} \mathrm{~mol}^{-1}$ (Ferrannini 1988)]. This decrease in glycogen concentration is more than $50 \%$ lower than after $24 \mathrm{~h}$ of moderate-intensity exercise (Enqvist et al. 2010) and $\sim 25 \%$ lower than after $2 \mathrm{~h}$ of cycling at $179 \mathrm{~W}$ (DeBock et al. 2007). These discrepancies in glycogen content changes during a race might be explained by differences in carbohydrate intake, exercise intensity and training status of the participants (Rapoport 2010). Such differences were actually existent between the present and the aforementioned studies. First, the calculated energy intake per hour in both mentioned studies is markedly higher than the one calculated for the participants in the current study (1.5 and 1.3 vs. $0.9 \mathrm{MJ}$, respectively). However, our participants had approximately the same carbohydrate intake per hour as compared to the one estimated for the participants in the study by Enqvist et al. (2010). Therefore, it is unlikely that differences in the reliance on glycogen stores made up for the apparent discrepancy. Second, exercise intensity during an Ironman race, expressed as percentage of maximal heart rate, is higher ( $83 \%$; Laursen et al. 2006) than the one (66\%) reported by Enqvist et al. (2010). Therefore, it seems likely that more glycogen is used during an Ironman race relative to the laboratory testing. Third, the ultraendurance trained athletes with international merits in the study by Enqvist et al. (2010) should clearly have a higher training status than our participants. Accordingly, they might be more efficient with respect to glycogen sparing because of higher lipid oxidation rates and utilization. Consequently, based on these considerations and the lower decrease in glycogen concentration in the present study, we suppose that our calculation rather underestimated than overrated glycogen consumption.

The lost fat mass accounted for $\sim 17 \mathrm{MJ}$ (caloric equivalent of fat: $\sim 38 \mathrm{~kJ} \mathrm{~g}^{-1}$ ) of energy expenditure during the Ironman competition. Energy uptake during the competition was $\sim 10 \mathrm{MJ}$ (see "Results"). This value is markedly lower than the one $(\sim 16 \mathrm{MJ})$ reported in a former study by Kimber et al. (2002). Since a decrease in protein mass is unlikely to have occurred, the remaining energy was obtained from muscle and possibly liver glycogen. Thus, the $1.4 \mathrm{~kg}$ decrease in lean mass reflects the decrease in glycogen. As mentioned above, each gram of stored glycogen binds 3-4 g of water (Olsson and Saltin 1970 ). Hence, $\sim 0.350-0.467 \mathrm{~kg}$ of glycogen, of which $\sim 0.170 \mathrm{~kg}$ (i.e. $\sim 50 \%$ ) in the legs, were used during the competition. These results thus indicate that the multi- disciplinary nature of triathlon might represent a major metabolic stress not only for the legs but also for core and upper body muscles and/or that during prolonged endurance exercise glycogenolysis in non-exercising muscles occurs (Kohler and Boutellier 2004). Since the mentioned amount of glycogen has an energy potential of 5.8-7.8 MJ, it can be calculated that our participants totally expended about $34 \mathrm{MJ}$. This value is lower than the one (41.9 MJ) calculated by Kimber et al. (2002). The discrepancy could be due to the different calculation methods. Kimber et al. (2002) used estimated oxygen consumption during swimming and recorded heart rate during cycling and running to calculate energy expenditure using previously determined regression equations. In this model, a fatigue- or dehydration-induced increase in heart rate during competition would lead to a higher $\dot{V} \mathrm{O}_{2}$ and finally, to an overestimated energy expenditure. We circumvented this problem by calculating energy expenditure directly from the measured changes in solid masses and estimated energy intake. Clearly, energy intake estimation relies on the accuracy of the participants' information, and thus may account in part for the observed discrepancy between studies. We tried to minimize the potential error associated with the estimation of energy intake by providing the athletes with nutriment questionnaires, in which all the possible foods and fluids provided by the organizer were listed as a function of each single aid station. Furthermore, the participants were asked to list all additional (i.e. not provided by the organizer) nutriments and supplements consumed. Despite of these precautions, we cannot exclude underestimation of energy intake by our participants in this study. Underestimation of energy intake in this study may represent a reason for the lower value in total energy expenditure as obtained by Kimber et al. (2002).

It can be predicted from our data that the participants were losing $\sim 0.8 \mathrm{dm}^{3}$ of water $\mathrm{h}^{-1}\left[0.33 \mathrm{dm}^{3}\right.$ of water $\mathrm{h}^{-1}$ during swimming (Maughan et al. 2009) and $0.89 \mathrm{dm}^{3}$ of water $\mathrm{h}^{-1}$ during cycling and running (Montain et al. 2006)], while consuming $0.7 \mathrm{dm}^{3}$ of fluid $\mathrm{h}^{-1}$ during the $11 \mathrm{~h}$ of competition. Consequently, the estimated total water loss was $\sim 1.0 \mathrm{dm}^{3}$, a volume corresponding to the water released upon the calculated glycogen breakdown. The calculated water loss was associated with at least four indicators of dehydration. First, urine specific gravity was increased after the Ironman event. Urine specific gravity is an indicator for how much the kidney concentrates the waste molecules in the urine. According to the national athletic trainers' association position statement (2000), the urine specific gravity values of our participants showed minimal dehydration before the competition and significant dehydration after the event. Our post competition values were higher than in previous 
reports (Rogers et al. 1997; Laursen et al. 2006). Second, there was an increase in plasma $\left[\mathrm{Na}^{+}\right]$, which might have been due to a decrease in body fluid or a high intake of sodium. Based on the aforementioned environmental conditions, the triathletes were losing $\sim 0.8 \mathrm{dm}^{3}$ of water $\mathrm{h}^{-1}$, which led to a sweat induced loss of $\sim 400 \mathrm{mg}$ of sodium per hour (Montain et al. 2006). The estimated sodium intake was close to this value, making an over intake of sodium unlikely to have occurred. It follows that the decrease in body fluid was responsible for the increase in plasma $\left[\mathrm{Na}^{+}\right]$. Third, plasma osmolality, which is a measure for the water and electrolyte balance of the body, was increased. Fourth, there was a significant negative correlation between the percentage change in plasma osmolality and the percentage change in body mass. Linear regression revealed that $59 \%$ of the variability in plasma osmolality could be explained by the change in body mass (Fig. 2). The calculated loss of $\sim 1.0 \mathrm{dm}^{3}$ of water was substantially more than the $0.6 \mathrm{dm}^{3}$ previously measured by Knechtle et al. (2010). In summary, the loss of body mass in our male Ironman triathletes could be attributed to a reduction in fat mass and a concomitant loss of glycogen as fuel for energy production, as well as a loss of body water, which led to dehydration. The $2.4 \%$ decrease in body mass is well in the range ( -2.3 to $-4.6 \%)$ of former investigations (Laursen et al. 2006; Rogers et al. 1997; Speedy et al. 2001).

During the race, our participants consumed fluid ad libitium. This type of consumption could lead to fluid overload or undersupply. Especially fluid overload might be a potential health risk, as it has been shown that it could lead to hyponatremia- a life-threatening condition that sometimes occurs during endurance events (Speedy et al. 2000). Fluid overload and hyponatremia are associated with an increase in total body mass (Speedy et al. 2000). Contrary to these findings, total body mass was not increased in any of the participants while plasma $\left[\mathrm{Na}^{+}\right]$ even increased. The latter probably occurred because of fluid loss, since calculated $\mathrm{Na}^{+}$intake matched calculated $\mathrm{Na}^{+}$loss. We conclude that a slightly too low fluid intake in conjunction with a balanced $\mathrm{Na}^{+}$intake and (sweatinduced) loss during the Ironman may have prevented the participants from developing hyponatremia.

Bone mass and geometry, and thus bone strength, are believed to be higher in athletes than in the sedentary population (Suominen 1993). However, Barry and Kohrt (2008) reported that male cyclists lose areal bone mineral density, as measured by DXA, during 1 year of training, and they suggested that this is due to excessive dermal calcium loss following prolonged sweating (Barry and Kohrt 2008). In this context it is principally of interest, whether extreme endurance events can make an acute impact on absorptiometric bone measures. In the present report, bone mineral content, bone mineral density and bone area remained constant at all measured sites along the tibia. Our data thus indicate that the Ironman race, which was associated with strong sweating, had no effect on absorptiometric bone parameters.

In this study, we applied for the first time the gold standards for whole-body composition and lower limb density measurements to assess body composition changes during an Ironman race. The calculations for energy expenditure are based on the outcomes of these measurements. As it is not possible to measure energy expenditure directly during this field event, the calculation from body composition changes might be a promising avenue. Certainly, further research is needed, especially to resolve the apparent discrepancies in the calculation of energy expenditure that might arise from the use of different methods.

\section{Conclusions}

In conclusion, an Ironman triathlon led to a loss of fat mass, which provided $\sim 50 \%$ of whole energy expenditure. The decrease in lean mass mainly occurred in the legs and reflected a loss of glycogen. Glycogen loss was paralleled by a decrease in muscle density and water, the latter causing dehydration. Therefore, an Ironman event led to substantial changes in body composition. The standardized measurement of body composition with DXA and pQCT before and after an Ironman event provided more detailed insights into the catabolism of fat and lean mass during extreme endurance exercise.

Acknowledgments The authors thank Andrea Wirth, Birte Ellenrieder, Claudia Mrazek, Jolanda Bürge and Christoph Villiger for the technical assistance during the race.

Conflict of interest The authors declare that they have no conflict of interest.

\section{References}

Anliker E, Dick C, Rawer R, Toigo M (2012) Effects of jumping exercise on maximum ground reaction force and bone in 8 - to 12-year-old boys and girls: a 9-month randomized controlled trial. J Musculoskelet Neuronal Interact 12:56-67

Augat P, Gordon CL, Lang TF, Iida H, Genant HK (1998) Accuracy of cortical and trabecular bone measurements with peripheral quantitative computed tomography (pQCT). Phys Med Biol 43:2873-2883

Barry DW, Kohrt WM (2008) BMD decreases over the course of a year in competitive male cyclists. J Bone Miner Res 23:484-491

Beelen M, Zorenc A, Pennings B, Senden JM, Kuipers H, van Loon LJ (2011) Impact of protein coingestion on muscle protein synthesis during continuous endurance type exercise. Am J Physiol Endocrinol Metab 300:E945-E954 
Bushberg JT, Seibert AT, Leidholdt EM Jr, Boone JM (2002) The essential physics of medical imaging. Lippincott Williams \& Wilkins, Philadelphia

Bylund-Fellenius AC, Ojamaa KM, Flaim KE, Li JB, Wassner SJ, Jefferson LS (1984) Protein synthesis versus energy state in contracting muscles of perfused rat hindlimb. Am J Physiol 246(4 Pt 1):E297-E305

Carraro F, Suart CA, Hartl WH, Rosenblatt J, Wolfe RR (1990) Effect of exercise and recovery on muscle protein synthesis in human subjects. Am J Physiol 259(4 Pt 1):E470-E476

Casa DJ, Armstrong LE, Hillman SK, Montain SJ, Reiff RV, Rich BSE, Roberts WO, Stone JA (2000) National athletic trainers' association position statement: fluid replacement for athletes. J Athl Train 35:212-224

DeBock K, Derave W, Ramaekers M, Richter EA, Hespel P (2007) Fiber type-specific muscle glycogen sparing due to carbohydrate intake before and during exercise. J Appl Physiol 102:183-188

Enqvist JK, Mattsson CM, Johansson PH, Brink-Elfegoun T, Bakkman L, Ekblom BT (2010) Energy turnover during 24 hours and 6 days of adventure racing. J Sports Sci 28:947-955

Essen B (1977) Intramuscular substrate utilization during prolonged exercise. Ann N Y Acad Sci 301:30-44

Faul F, Erdfelder E, Buchner A, Lang A (2007) G*Power 3: a flexible statistical power analysis program for the social, behavioral, and biomedical sciences. Behav Res Methods 39:175-191

Ferrannini E (1988) The theoretical bases of indirect calorimetry: a review. Metabolism 37:287-301

Goodpaster BH, Kelley DE, Thaete FL, He J, Ross R (2000) Skeletal muscle attenuation determined by computed tomography is associated with skeletal muscle lipid content. J Appl Physiol 89:104-110

Hargreaves M, Snow R (2001) Amino acids and endurance exercise. Int J Sport Nutr Exerc Metab 11:133-145

Jeng CL, Thawait GK, Kwon JY, Machado A, Boyle JW, Campbell J, Carrino JA (2012) Relative strength of the calf muscles based on MRI volume measurements. Foot Ankle Int 33:394-399

Kimber NE, Ross JJ, Mason SL, Speedy DB (2002) Energy balance during an ironman triathlon in male and female triathletes. Int $\mathrm{J}$ Sport Nutr Exerc Metab 12:47-62

Kirchhoff E (2002) Online-publication of the german food composition table "Souci-Fachmann-Kraut" on the Internet. J Food Compos Anal 15:465-472

Knechtle B, Wirth A, Knechtle P, Rosemann T (2009) Increase of total body water with decrease of body mass while running $100 \mathrm{~km}$ nonstop-formation of edema? Res Q Exerc Sport 80:593-603

Knechtle B, Baumann B, Wirth A, Knechtle P, Rosemann T (2010) Male ironman triathletes lose skeletal muscle mass. Asia Pac J Clin Nutr 19:91-97

Kohler G, Boutellier U (2004) Glycogen reduction in non-exercising muscle depends on blood lactate concentration. Eur J Appl Physiol 92:548-554

Koopman R, Pannemans DLE, Jeukendrup AE, Gijsen AP, Senden JMG, Halliday D, Saris WHM, van Loon LJC, Wagenmakers AJM (2004) Combined ingestion of protein and carbohydrate improves protein balance during ultra-endurance exercise. Am J Physiol Endorcinol Metab 287:E712-E720

Laursen PB, Suriano R, Quod MJ, Lee H, Abbiss CR, Nosaka K, Martin DT, Bishop D (2006) Core temperature and hydration status during ironman triathlon. Br J Sports Med 40:320-325
Lepers R (2008) Analysis of Hawaii ironman performances in elite triathletes from 1981 to 2007. Med Sci Sports Exerc 40:1828-1834

Lott JA, Johnson WR, Luke KE (1995) Evaluation of an automated urine chemistry reagent-strip analyzer. J Clin Lab Anal 9:212-217

Maganaris CN, Baltzopoulos V, Ball D, Sargeant J (2001) In vivo specific tension human skeletal muscle. J Appl Physiol 90:865-875

Maughan RJ, Dargavel LA, Hares R, Shirreffs SM (2009) Water and salt balance of well-trained swimmers in training. Int J Sports Nutr Exerc Metab 19:598-606

Montain SJ, Cheuvront SN, Sawka MN (2006) Exercise associated hyponatremia: quantitative analysis to understand the aetiology. Br J Sports Med 40:98-106

Mougios V (2006) Exercise biochemistry. Human Kinetics, Champaign

Nana A, Slater GJ, Hopkins WG, Burke LM (2012a) Effects of daily activities on dual-energy X-ray absorptiometry measurements of body composition in active people. Med Sci Sports Exerc 44:180-189

Nana A, Slater GJ, Hopkins WG, Burke LM (2012b) Effects of exercise sessions on DXA measurements of body composition in active people. Med Sci Sports Exerc 45:178-185

Olsson KE, Saltin B (1970) Variation in total body water with muscle glycogen changes in man. Acta Physiol Scand 80:11-18

Pietrobelli A, Formica C, Wang Z, Heymsfield SB (1996) Dualenergy X-ray absorptiometry body composition model: review of physical components. Am J Physiol 271(6 Pt 1):E941-E951

Rapoport BI (2010) Metabolic factors limiting performance in marathon runners. PLoS Comput Biol 6:e1000960

Rogers G, Goodman C, Rosen C (1997) Water budget during ultraendurance exercise. Med Sci Sports Exerc 29:1477-1481

Romijn JA, Coyle EF, Sidossis LS, Gastaldelli A, Horowitz JF, Endert E, Wolfe RR (1993) Regulation of endogenous fat and carbohydrate metabolism in relation to exercise intensity and duration. Am J Physiol Endocrinol Metab 265:E380-E391

Speedy DB, Rogers IR, Noakes TD, Wright S, Thompson JMD, Campbell R, Hellemans I, Kimber NE, Boswell DR, Kuttner JA, Safih S (2000) Exercise-induce hyponatremia in ultradistance triathletes is caused by inappropriate fluid retention. Clin $\mathbf{J}$ Sports Med 10:272-278

Speedy DB, Noakes TD, Kimber NE, Rogers IR, Thompson JM, Boswell DR, Ross JJ, Campbell RG, Gallagher PG, Kuttner JA (2001) Fluid balance during and after an ironman triathlon. Clin J Sport Med 11:44-50

Strauss MB, Davis RK, Rosenbaum JD, Rossmeisl EC (1951) Water diuresis produced during recumbency by the intravenous infusion of isotonic saline solution. J Clin Invest 30:862-868

Suominen H (1993) Bone mineral density and long term exercise. An overview of cross-sectional athlete studies. Sports Med 16: 316-330

Ward SR, Lieber RL (2005) Density and hydration of fresh and fixed human skeletal muscle. J Biochem 38:2317-2320

Wells JC, Fewtrell MS (2006) Measuring body composition. Arch Dis Child 91:612-617

Wolfe RR, Goodenough RD, Wolfe MH, Royle GT, Nadel ER (1982) Isotopic analysis of leucine and urea metabolism in exercising humans. J Appl Physiol 52:458-466 